\title{
Evaluation of a National Programme to Enhance Shared Decision-Making Skills among Junior Medical Doctors in Denmark: A Mixed Methods Study of Satisfaction, Usefulness, and Dissemination of Learning Outcomes in Clinical Practice
}

Maria Helene Jacobsen ( $\sim$ mariahelene.jacobsen@hotmail.com )

University of Copenhagen

Cecilie Sommer

University of Copenhagen

Siw Anna Wernberg

University of Copenhagen

Helga Schultz

North Zealand Hospital

Sofie Charlotte Fage Hjortø

Slagelse Hospital

Maria Kristiansen

University of Copenhagen

Research Article

Keywords: shared decision-making, patient-centred care, SDM training programme, mixed methods study,

Evaluation

Posted Date: October 6th, 2021

DOl: https://doi.org/10.21203/rs.3.rs-919620/v1

License: (9) This work is licensed under a Creative Commons Attribution 4.0 International License.

Read Full License 


\section{Abstract \\ Background}

Shared Decision-Making (SDM) is a cornerstone in patient-centred care and there is an increase in programmes aiming to enhance clinicians' abilities to engage in SDM. However, the evidence of such programmes' effectiveness on clinicians' use of SDM in clinical practice is sparse. The SDM Ambassador course, developed and facilitated by the Danish Association of Junior Doctors in Denmark (Junior Doctors Denmark) is a Danish SDM training programme for junior medical doctors (JMDs). This study aims to evaluate the SDM Ambassador course, with a focus satisfaction, usefulness, and dissemination of learning outcomes in clinical practice.

\section{Methods}

This study is a mixed methods study consisting of an online survey followed by semi-structured interviews. The participants of this study were JMDs who had trained to be SDM ambassadors between May 2016 and September $2020(n=185)$. The ambassadors were invited to participate in the survey and 112 ambassadors completed the survey, corresponding to a response rate of $61 \%$. Descriptive statistics and $\chi^{2}$-tests were conducted. Subsequently, purposive sampling was used to identify 10 ambassadors for interviews. The interviews were transcribed, encoded and subsequently analysed thematically. Finally, the quantitative and qualitative results were integrated.

\section{Results}

Overall, the ambassadors were satisfied with their learning outcomes and experienced a greater capacity to unfold the perspectives of their patients. A majority (79\%) reported that they had used SDM in their clinical practice with patients, and 59\% had disseminated SDM to their colleagues. The usefulness and dissemination of learning outcomes in the clinic were shaped by the ambassadors' perceptions of their moderate professional experience, and constrained by structural and cultural conditions in the context of their clinical practice.

\section{Conclusion}

Despite overall satisfaction with their learning outcomes, several ambassadors experienced conditions constraining the translation of their learning outcomes into clinical practice. To improve the efficacy of the training programme, continuous refresher courses should be added while enhanced support at organisational and political levels is necessary for SDM to become an integral feature of the clinical encounter. 


\section{Trial registration:}

Not applicable.

\section{Background}

SDM is a cornerstone of patient-centred healthcare and is increasingly highlighted as an ideal model for making health-related decisions in encounters between medical doctors (MDs) and their patients $(1,2)$. SDM is referred to as a partnership between MD and patient, where the patient is presented with available treatment options based on existing evidence and is informed about the differences between them, including advantages and disadvantages (3). The MD and the patient then make decisions together, choosing the option best suited for the patient's preferences and life circumstances $(3,4)$.

Several rationales for implementing SDM in healthcare services have been highlighted in the literature. In particular, there is an ethical rationale for SDM, which argues that SDM ensures respect for the individual's autonomy, and justice by ensuring that the patient's preferences and wishes are emphasised in the care and treatment they receive $(3,4)$. Other rationales include that SDM may increase satisfaction among patients (5-7), improve the working environment for healthcare professionals (8), and ensure a more efficient use of resources (9). Thus, SDM is perceived as an approach to address some of the challenges that healthcare systems all over the world are facing, including ageing populations and an increasing number of people living with one or more chronic illnesses.

In spite of these rationales and the broad interest in SDM, it is not routine practice in healthcare, either in Denmark or internationally $(2,10,11)$. Conditions related to the structure of healthcare systems and to patients and MDs have a great impact on the extent to which SDM is able to develop in clinical practice (12). Several studies suggest that enhancing healthcare professionals' SDM knowledge and skills through training is important for implementing SDM in healthcare $(13,14)$. The number of SDM training programmes for healthcare professionals has therefore increased rapidly worldwide; however evidence about the effects of these training programmes is sparse, as only a few have been evaluated, and even fewer evaluations have been published (15). Among the training programmes targeting MDs that have been evaluated, no clear effect on knowledge and skills has been shown (16). Further, published evaluations of SDM training programmes are difficult to compare, due to differences in evaluation design and strategies (10).

In Denmark, the trade union 'Junior Doctors Denmark' developed an SDM training programme in 2016, called the 'SDM Ambassador course', training junior doctors to become ambassadors in SDM. The aim of the course is to provide the ambassadors with the knowledge and skills to use SDM in clinical encounters with patients and disseminate SDM among colleagues. and thereby contribute to enhancing the use of SDM in the Danish healthcare system.

Thus, the objective of this mixed methods study is to evaluate the SDM Ambassador course, focusing on satisfaction with learning outcomes among the SDM ambassadors, and their experiences with using 
SDM with patients and disseminating it among colleagues. To achieve this the following questions will be addressed in this study:

1. To what extent are the ambassadors satisfied with their learning outcomes from the SDM Ambassador course, and how do they describe their satisfaction with the learning outcome?

2. To what extent do the ambassadors use SDM with patients in clinical practice, and how do they experience the SDM that does take place?

3. To what extent do the ambassadors disseminate SDM among colleagues, and how do they experience the dissemination of SDM that does take place among colleagues?

\section{Methods}

\section{Aim, design and setting of the study}

We conducted this study with an explanatory sequential mixed methods design consisting of two phases with the aim of evaluating the SDM Ambassador course (17). The first phase consisted of collecting and analysing quantitative data from an online survey, followed by a second phase in which qualitative data from semi-structured interviews was generated and analysed (Figure 1). The quantitative data was collected from 5th October to 15th November, 2020. At the end of the survey respondents were able to indicate whether they wanted to participate in a follow-up interview. The generation of the qualitative data occurred from 18th November to 27th November, 2020.

The SDM Ambassador course is a voluntary programme that was established in May 2016 by Junior Doctors Denmark as an offer to their members across all medical specialities. To participate in the SDM Ambassador course doctors need to be a member of the association and promise to teach SDM to their colleagues. The SDM Ambassador course consists of two days of SDM training, with only the first day of training being obligatory to become an ambassador. The training focuses on both the theoretical and practical aspects of SDM, including communication skills and the use of decision aids.

\section{Characteristics of participants}

Both former and active ambassadors, trained between May 2016 and September 2020, were invited to participate in the study. This resulted in a total of 185 ambassadors ( 55 former and 130 active) receiving an online survey. In total, 29 wished to participate in an interview, of whom we selected 10 ambassadors by a maximum variation sampling strategy, to best reflect a diverse group. This meant that we sampled interviewees who differed with regard to their answers to questionnaire items concerning learning outcomes, usefulness and dissemination of SDM, as well as with regard to their gender, medical speciality and the number of training days they had attended.

\section{Data Collection}

The ambassadors' names and email addresses were obtained via Junior Doctors Denmark's membership system, with consent from the ambassadors themselves. An invitation was sent to the 185 ambassadors 
by an email including a link to the online survey. Two weeks after the distribution of the online survey, a reminder was sent out, with a second reminder after a further one week interval. After the second reminder, the response rate was approximately $30 \%$ only. Then, the ambassadors who had not completed the survey were contacted by telephone; or were sent a text message that encouraged them to participate if they had not answered the telephone call. This contributed to a total response rate of $61 \%$. The interviews were conducted and recorded over Zoom $(n=6)$, telephone $(n=3)$, or physically at the university campus $(n=1)$; and lasted between 25 and 60 minutes. Figure 2 presents a flow diagram of the participants in this study.

The online survey (see additional file 1) was developed in SurveyXact and included information about the evaluation and its' purpose, data processing and storage, and a declaration of consent form. The survey was initiated with items relating to the demographic characteristics of the ambassadors (five items) as well as items about their participation in the SDM Ambassador course (seven items). This study reports on the findings related to items concerning the ambassadors' satisfaction with their learning outcome, and their use and dissemination of SDM in clinical practice. Satisfaction with the learning outcome was measured by three items, based on whether the ambassadors were satisfied with their SDM knowledge, competencies, and communication skills, respectively. This was assessed by five response categories, from 'strongly disagree' to 'strongly agree'. The usefulness and dissemination of SDM was measured by asking the respondents whether they had used SDM knowledge and competencies gained from the Ambassador course in their clinical practice, or disseminated their SDM knowledge and competencies in their clinical context. Respondents were able to answer 'Yes/No' and 'Do not know'. If they replied 'No', they were asked a question about the reason why they had not used or disseminated SDM, with predefined response categories and a free text field. For dissemination of SDM, there was an additional item for the ambassadors who stated that they had disseminated SDM, concerning how they had disseminated it, for which there were predefined response categories and a free text field. The content validity of the questionnaire was assessed by a pre-test with a steering committee from Junior Doctors Denmark with in-depth knowledge about the medical profession and the Ambassador course $(n=3)$, and a pilot test with persons from the target group $(n=4)$.

The subsequent semi-structured interviews were based on a standard interview guide, which was adapted to the individual interviewee's questionnaire responses. The standard interview guide contained an introduction and the themes investigated in this study: implications for practice, including satisfaction with learning outcomes, usefulness of SDM, and dissemination of SDM. Each theme included a representation of the interviewee's survey response, whereafter they were asked to elaborate. The interview guide served as a guideline for exploring the pre-selected quantitative results, while also providing the possibility for the interviewees to narrate new aspects in their responses. The interview guide was discussed at a steering committee meeting and a pilot test with an ambassador from Junior Doctors Denmark was conducted.

\section{Analysis}


Survey data was retrieved from SurveyXact to SPSS (version 27), where the data was filtered and recoded. Descriptive statistics were followed by $\chi^{2}$-tests to examine the correlations between the demographic variables and the satisfaction with learning outcomes, the usefulness, and the dissemination of SDM, respectively. The processing of the quantitative data formed the basis for the planning of the qualitative phase, including sampling, interview guide and analytical focus. All qualitative interviews were transcribed, and the qualitative data was imported into NVivo (version 20.3.2). The individual interviews were encoded independently by two researchers. A thematic network analysis was conducted, based on the model presented by Attride-Stirling (2001) (18). After processing both survey and interview data, we integrated the results.

\section{Results}

Of the 185 ambassadors invited to participate in this study, 112 responded to the survey, corresponding to a response rate of $61 \%$, out of which 10 ambassadors participated in interviews. The typical participant was a woman aged 35, who was in specialist training to be a general practitioner, had become an ambassador in 2018, participated in the first day of training only, and was still a part of the ambassador programme (Table 1). 
Table 1

Characteristics of the study population

\begin{tabular}{|c|c|}
\hline Sex, n (\%) & $94(84)$ \\
\hline \multicolumn{2}{|l|}{ Female } \\
\hline Age, $n(\%)$ & $10(9)$ \\
\hline$\leq 29$ & $61(54)$ \\
\hline $30-34$ & $33(22)$ \\
\hline $35-39$ & $17(15)$ \\
\hline$\geq 40$ & 35 \\
\hline \multicolumn{2}{|l|}{ Mean } \\
\hline Employer ${ }^{A}, n(\%)$ & $6(5)$ \\
\hline North Denmark Region & $26(23)$ \\
\hline Central Denmark Region & $24(21)$ \\
\hline Region of Southern Denmark & $10(9)$ \\
\hline Region Zealand & $41(37)$ \\
\hline Capital Region of Denmark & $8(7)$ \\
\hline General practice & $3(3)$ \\
\hline Central government (universities, government agency, etc.) & $1(1)$ \\
\hline Unemployed & $2(2)$ \\
\hline \multicolumn{2}{|l|}{ Other } \\
\hline Level of education, $n(\%)$ & $3(3)$ \\
\hline Internship & $28(25)$ \\
\hline Introductory position & $53(47)$ \\
\hline Specialist training & $7(6)$ \\
\hline Medical specialist & $10(9)$ \\
\hline Clinical assistant/research position & $9(8)$ \\
\hline Unclassified position & $2(2)$ \\
\hline \multicolumn{2}{|l|}{ Other } \\
\hline \multicolumn{2}{|l|}{ A Multiple response allowed. } \\
\hline${ }^{B}$ Corresponding to year of completion of the first day of $S[$ & \\
\hline
\end{tabular}




\begin{tabular}{|c|c|}
\hline \multicolumn{2}{|l|}{ Female } \\
\hline Medical speciality, n (\%) & $31(28)$ \\
\hline General medicine & $27(24)$ \\
\hline Medical specialities & $21(19)$ \\
\hline Surgical specialities & $14(13)$ \\
\hline Internal medical specialities & $8(7)$ \\
\hline Paraclinical specialities & $7(6)$ \\
\hline Emergency medicine & $3(3)$ \\
\hline \multicolumn{2}{|l|}{ Other } \\
\hline Year of enrolment in the Ambassador course ${ }^{\mathrm{B}}, \mathrm{n}(\%)$ & $22(20)$ \\
\hline 2016 & $17(15)$ \\
\hline 2017 & $32(29)$ \\
\hline 2018 & $24(21)$ \\
\hline 2019 & $17(15)$ \\
\hline \multicolumn{2}{|l|}{2020} \\
\hline Days of SDM training completed, $n(\%)$ & $76(68)$ \\
\hline First day of SDM training & $36(32)$ \\
\hline \multicolumn{2}{|l|}{ First and second day of SDM training } \\
\hline Enrolled in the Ambassador course at time of data collection, $n(\%)$ & $75(67)$ \\
\hline Yes & $17(15)$ \\
\hline No & $20(18)$ \\
\hline \multicolumn{2}{|l|}{ Unknown } \\
\hline Total, N (\%) & $112(100)$ \\
\hline A Multiple response allowed. & \\
\hline
\end{tabular}

Satisfaction with learning outcomes 
Most of the survey respondents were satisfied with their SDM learning outcomes from the ambassador course: knowledge (73\%), competencies (57\%), and communication skills $(66 \%)$. Thus, fewer respondents were satisfied with their competencies within SDM than with their knowledge and communication skills. Several respondents indicated that they were neither satisfied nor dissatisfied with their SDM learning outcomes: knowledge (17\%), competencies (29\%), and communication skills (25\%).

Associations between the respondents' satisfaction with their learning outcomes and their use and dissemination of SDM with patients and among colleagues are shown in Table 2. The majority of the respondents who had used SDM in their clinical practice were satisfied with their learning outcomes: knowledge (76\%), competencies (61\%), and communication skills (68\%). Most of the respondents who indicated that they had disseminated SDM in their clinical practice were satisfied with their learning outcomes: knowledge (79\%), competencies (64\%), and communication skills (74\%). Of the respondents who indicated that they had not disseminated SDM a considerable proportion was satisfied with their learning outcomes: knowledge (65\%), competencies (47\%), and communication skills (56\%). Neither of the chi-square tests were significant (Table 2). 
Table 2

Associations between the respondents' satisfaction with learning outcomes and use and dissemination of SDM

\begin{tabular}{|c|c|c|c|}
\hline $\begin{array}{l}\text { Use of SDM with patients in clinical } \\
\text { practice }\end{array}$ & $\begin{array}{l}\text { Used SDM, n } \\
\text { (\%) }\end{array}$ & Not used SDM, n (\%) & $\begin{array}{l}\text { Unknown, } \\
\text { n (\%) }\end{array}$ \\
\hline Satisfaction with SDM knowledge, $p=0.27$ & $67(76)$ & $11(61)$ & $4(67)$ \\
\hline Satisfied & $14(16)$ & $3(16)$ & $2(33)$ \\
\hline Neither satisfied nor dissatisfied & $7(8)$ & $4(22)$ & $0(0)$ \\
\hline $\begin{array}{l}\text { Dissatisfied } \\
\text { Total }\end{array}$ & $88(100)$ & $18(100)$ & $6(100)$ \\
\hline $\begin{array}{l}\text { Satisfaction with SDM competencies, } \\
\mathbf{p}=0.20 \\
\text { Satisfied } \\
\text { Neither satisfied nor dissatisfied } \\
\text { Dissatisfied } \\
\text { Total }\end{array}$ & $\begin{array}{l}54(61) \\
24(27) \\
10(12) \\
88(100)\end{array}$ & $\begin{array}{l}6(33) \\
7(39) \\
5(28) \\
18(100)\end{array}$ & $\begin{array}{l}4(67) \\
1(16) \\
1(16) \\
6(100)\end{array}$ \\
\hline $\begin{array}{l}\text { Satisfaction with SDM communication } \\
\text { skills, } \mathbf{p}=\mathbf{0 . 2 8} \\
\text { Satisfied } \\
\text { Neither satisfied nor dissatisfied } \\
\text { Dissatisfied } \\
\text { Total }\end{array}$ & $\begin{array}{l}60(68) \\
22(25) \\
6(7) \\
88(100)\end{array}$ & $\begin{array}{l}10(56) \\
4(22) \\
4(22) \\
18(100)\end{array}$ & $\begin{array}{l}4(67) \\
2(33) \\
0(0) \\
6(100)\end{array}$ \\
\hline Dissemination of SDM among colleagues & $\begin{array}{l}\text { Disseminated } \\
\text { SDM, n (\%) }\end{array}$ & $\begin{array}{l}\text { Not disseminated SDM, } \\
\mathrm{n}(\%)\end{array}$ & $\begin{array}{l}\text { Unknown, } \\
\mathrm{n}(\%)\end{array}$ \\
\hline Satisfaction with SDM knowledge, $p=0.50$ & $52(79)$ & $28(65)$ & $2(67)$ \\
\hline Satisfied & $9(14)$ & $9(21)$ & $1(33)$ \\
\hline Neither satisfied nor dissatisfied & $5(7)$ & $6(14)$ & $0(0)$ \\
\hline Dissatisfied & $66(100)$ & $43(100)$ & $3(100)$ \\
\hline Total & & & \\
\hline
\end{tabular}




\begin{tabular}{|llll|}
\hline $\begin{array}{l}\text { Use of SDM with patients in clinical } \\
\text { practice }\end{array}$ & $\begin{array}{l}\text { Used SDM, } \mathbf{n} \\
(\%)\end{array}$ & Not used SDM, $\mathbf{n}(\%)$ & $\begin{array}{l}\text { Unknown, } \\
\mathbf{n}(\%)\end{array}$ \\
\hline $\begin{array}{l}\text { Satisfaction with SDM competencies, } \\
\mathbf{p}=\mathbf{0 . 4 2}\end{array}$ & $42(64)$ & $20(47)$ & $2(67)$ \\
Satisfied & $15(23)$ & $16(37)$ & $1(33)$ \\
Neither satisfied nor dissatisfied & $9(13)$ & $7(16)$ & $0(0)$ \\
Dissatisfied & $66(100)$ & $43(100)$ & $3(100)$ \\
Total & & & $1(33)$ \\
\hline $\begin{array}{l}\text { Satisfaction with SDM communication } \\
\text { skills, p=0.10 }\end{array}$ & $49(74)$ & $24(56)$ & $2(67)$ \\
Satisfied & $11(17)$ & $15(35)$ & $0(0)$ \\
Neither satisfied nor dissatisfied & $6(9)$ & $4(9)$ & $3(100)$ \\
Dissatisfied & $66(100)$ & $43(100)$ & \\
Total & & & \\
\hline
\end{tabular}

In the qualitative interviews, the ambassadors said that they had gained more in-depth knowledge about involving patients in decision-making, and that their interaction with their patients had improved. Yet several ambassadors found it difficult to assess their satisfaction with their SDM learning outcomes. They perceived SDM as an abstract concept and felt that their SDM skills could be further improved. This might be the reason why a relatively large proportion of respondents in the survey indicated that they were neither satisfied nor dissatisfied with their SDM learning outcomes. Several ambassadors felt that they had sufficient knowledge about SDM but that it was difficult to translate this knowledge into clinical practice. Table 3 shows the integration between the quantitative and qualitative data regarding the ambassadors' learning outcomes. 
Table 3

Data integration of results concerning learning outcomes

\begin{tabular}{|c|c|c|}
\hline $\begin{array}{l}\text { Quantitative } \\
\text { results }\end{array}$ & $\begin{array}{l}\text { Qualitative } \\
\text { findings }\end{array}$ & Data integration \\
\hline $\begin{array}{l}\text { Learning } \\
\text { outcomes }\end{array}$ & \multirow{12}{*}{$\begin{array}{l}\text { '.. I feel that I } \\
\text { have a good } \\
\text { contact with my } \\
\text { patients - it } \\
\text { gives me more } \\
\text { comfort.' } \\
\text { '.. I can certainly } \\
\text { improve.' }\end{array}$} & $\begin{array}{l}\text { Satisfaction with learning outcome is due to awareness of } \\
\text { patient involvement in the clinical encounter as well as the } \\
\text { experience of a better interaction with the patients. }\end{array}$ \\
\hline Knowledge & & \multirow{12}{*}{$\begin{array}{l}\text { SDM is a concept which is complex and to which } \\
\text { ambassadors find it hard to relate. The ambassadors } \\
\text { struggle with assessing their learning outcome due to the } \\
\text { lack of a basis for comparison. However, they feel that they } \\
\text { can always improve their skills. }\end{array}$} \\
\hline $73 \%$ satisfied & & \\
\hline $\begin{array}{l}17 \% \text { neither } \\
\text { satisfied nor } \\
\text { dissatisfied }\end{array}$ & & \\
\hline $\begin{array}{l}10 \% \\
\text { dissatisfied }\end{array}$ & & \\
\hline Competencies & & \\
\hline $57 \%$ satisfied & & \\
\hline $\begin{array}{l}29 \% \text { neither } \\
\text { satisfied nor } \\
\text { dissatisfied }\end{array}$ & & \\
\hline $\begin{array}{l}14 \% \\
\text { dissatisfied }\end{array}$ & & \\
\hline $\begin{array}{l}\text { Communication } \\
\text { skills: }\end{array}$ & & \\
\hline $66 \%$ satisfied & & \\
\hline $\begin{array}{l}25 \% \text { neither } \\
\text { satisfied nor } \\
\text { dissatisfied }\end{array}$ & & \\
\hline $9 \%$ dissatisfied & & \\
\hline
\end{tabular}

\section{Usefulness of shared decision-making}

In the survey, the majority of respondents (79\%) reported that they had used SDM with patients in clinical practice (Table 3). Among ambassadors who had not used SDM (18 survey respondents) the main reasons for not using SDM were lack of SDM knowledge, tools, and competencies (39\%), the perception that it was difficult to introduce new ways of working as a new employee in an established workplace $(28 \%)$, and lack of time (22\%); with the option of selecting more than one reason. In the interviews, the ambassadors explained that SDM could be used as both a mindset and a method. Several of the ambassadors emphasised that they mostly used SDM as a mindset in their encounter with patients. They found it more difficult to use SDM as a method, partly because they felt that they did not have the 
necessary SDM tools, such as decision aids. In the interviews, several contextual factors in the ambassadors' clinical practice were emphasised as decisive for whether and how the ambassadors translated their learning outcomes into use in clinical practice. These included time constraints, their medical speciality, and their professional experience and medical knowledge. Key points from the quantitative and qualitative results for the usefulness of SDM and the data integration are shown in Table 4.

Table 4

Data integration of results concerning the usefulness of SDM

Quantitative Qualitative findings Data integration
results

Use of SDM $\quad$... / carry the mindset in all my consultations...'

$79 \%$ have used SDM

$16 \%$ have

not used

SDM
'As a new doctor one will always think it is a challenge to provide guidance on a treatment you have not had a lot of experience with.'
Use of SDM by the ambassadors is felt to be easier as a mindset than as a method.

Personal characteristics of the doctor such as learning outcome and professional experience, as well as contextual conditions such as medical specialities and limited time, shape the ambassadors' use of SDM in the clinical encounter.

$5 \%$ do not

know

\section{Dissemination of shared decision-making}

More than half of the respondents (59\%) in the survey stated that they had disseminated SDM among colleagues (Table 3). $85 \%$ of the ambassadors indicated that they had told one or more colleagues about SDM and $67 \%$ had made presentations about SDM for their medical department. The main reasons for not disseminating SDM were issues related to the ambassadors' work practices, including competing work tasks (51\% out of 43 ), a belief that SDM did not fit into their clinical practice (26\%), and a feeling of insufficient knowledge and competencies to communicate about SDM (23\%). The ambassadors emphasised that they primarily disseminated SDM by telling colleagues about SDM and by teaching SDM in their medical departments. In particular, the interviewed ambassadors emphasised that they did not feel sufficiently equipped to disseminate SDM among their colleagues, as it was challenging to teach others something that they did not feel comfortable in using in practice themselves. This could explain why fewer respondents in the survey stated that they had disseminated SDM among colleagues than used SDM with patients in clinical practice. In the interviews, several ambassadors emphasised that they needed to be part of a network with other ambassadors to exchange ideas and discuss issues, for example by preparing and making presentations together. The ambassadors perceived various contextual factors in the clinical practice as being important for their dissemination of SDM. These included scheduled teaching sessions specifically to facilitate dissemination of SDM. However, the experience that presentations for colleagues were not sufficient to disseminate SDM, along with comments (especially 
from older colleagues) that 'we are already practicing SDM', were perceived as barriers. Key points from the quantitative and qualitative results for dissemination of SDM and the data integration are shown in Table 5.

Table 5

Data integration of results concerning the dissemination of SDM

Quantitative Qualitative findings Data integration
results

\section{Dissemination of SDM}

$59 \%$ have disseminated

SDM

$38 \%$ have not disseminated SDM

$3 \%$ do not know
'... I do not think I have found a good way to implement SDM in my everyday practice which has kept me from disseminating the message'

[about making a presentation among colleagues] '...Well, that

was interesting and then nothing happened.'

\section{Discussion}

\section{Main findings}

This study used mixed methods to evaluate junior doctors' satisfaction with their learning outcomes, as well as their use and dissemination of SDM among patients and colleagues, respectively, after participating in the SDM Ambassador course. In general, the ambassadors were satisfied with their learning outcomes, and the majority of the ambassadors indicated that they had used and disseminated SDM in their clinical practice. The context of the ambassadors' clinical practice was significant for their experience of usefulness and dissemination of SDM.

\section{Comparison with the literature}

The ambassadors' satisfaction with their learning outcomes from the Ambassador course is in line with the international literature, which shows that even short-term SDM training programmes have a positive effect on MDs' learning outcomes $(13,19-21)$. However, our results are not strictly comparable with the results of these studies as they are primarily collected from MDs within one medical specialism. Thus, our study contributes to a broader picture of the effects of training programmes on MDs' satisfaction with their learning outcomes. Also, our results showed that fewer ambassadors were satisfied with their competencies compared with their knowledge and communication skills within SDM. This finding was explained and nuanced in our interviews, in which several ambassadors said that it was difficult for them 
to apply their learning outcomes in their clinical practice, although they did have sufficient knowledge and materials about SDM. This indicates that short-term training programmes in SDM are not sufficient if MDs are to be equipped to use and disseminate SDM routinely in their clinical practice with patients and among colleagues.

This study showed that most of the ambassadors used (79\%) and disseminated (59\%) SDM following the Ambassador course. To our knowledge, only a few studies have examined whether and how MDs use and disseminate SDM, with patients and among colleagues respectively, after an SDM training programme. Studies have shown varied results which can be attributed to differences in study designs and methods of measurement $(19,22,23)$. Unlike our study, Körner et al. (2012) found that daily interaction with colleagues in relation to a train-the-trainer programme in SDM, for providers in executive positions, affected the number of healthcare professionals using SDM in clinical practice (23). Our results also indicate that there is not one shared understanding of what SDM is among MDs. Further, it is likely that the ambassadors are not aware that dissemination of SDM is a practice that can be carried out unintentionally when the ambassadors use SDM themselves, as they may inspire their colleagues to use it too. Overall, SDM is an ambiguous concept, which makes it difficult for MDs to assess the learning outcomes, use, and dissemination of SDM following a training programme.

Different conditions in the clinical context shaped the ambassadors' use and dissemination of SDM, including lack of time, the clinical situation, the medical hierarchy, and lack of clinical experience. These contextual conditions are known in the literature $(12,19,22,24)$. Thus, this study does make a contribution by confirming that these conditions also influence the ambassadors' usefulness and dissemination of SDM in the context of the Danish healthcare system. A short SDM training programme cannot alter these contextual conditions.

\section{Strengths and limitations}

This study should be considered within the context of its methodological strengths and limitations. We used mixed methods to carry out an in-depth evaluation of the Ambassador course. Our quantitative results provided a broad knowledge of the ambassadors' satisfaction with their learning outcomes, as well as the extent to which the ambassadors used and disseminated SDM in their clinical practice. These results were nuanced and contextualised by the interviews, which drew attention to several contextual conditions that shaped the ambassadors' perception of their learning outcomes, as well as their experiences with using and disseminating SDM. This comprehensive knowledge, gained from triangulating quantitative and qualitative data, underlines the strength of our mixed methods design.

Our data collection approach has led to a relatively high response rate $(61 \%)$, which reduces the risk of selection bias in our results. However, the Ambassador course is a voluntary training programme, from which it can be assumed that the ambassadors had a positive attitude towards SDM in advance. Thus, our results cannot be generalised to every member of Junior Doctors Denmark. Further, the crosssectional design does not permit an assessment of causality within our results. It is likely that the ambassadors' satisfaction with their learning outcomes, use, and dissemination of SDM are not solely a 
result of their participation in the Ambassador course. However, we consider our use of maximum variation sampling as a strength, regarding the study's applicability. By ensuring as much variation as possible among the interviewed ambassadors, in terms of their learning outcomes, use and dissemination of SDM, we have achieved a more representative evaluation of the Ambassador course than if we had only interviewed those who, for example, were the most satisfied with the ambassador course.

Our study focuses on JMDs' experiences with SDM training. Future studies should therefore investigate whether the patients feel more included in health-related decisions and experience better treatment because of SDM training programmes. In the long run interventions and evaluations should target multiple health professional, including MDs; as well as patients and their relatives. However, the interventions need to take place in a context where the cultural and structural conditions that work as barriers for SDM are addressed. Thus, interventions need to be accompanied by organisational and political support so that the clinical context facilitates both the use and dissemination of SDM.

\section{Future perspectives}

Based on this study's results, future short-term SDM training programmes should supplement SDM teaching with regular refresher courses that can be taken online, to accommodate MDs' busy and changeable professional and everyday lives. Further, it is relevant to discuss whether it is appropriate for relatively young and newly-qualified MDs to be agents of change in the Ambassador course, as this study has shown that this group of MDs lacks impact in their clinical environments, especially among their older and more experienced colleagues. Thus, future SDM programmes should focus on targeting MDs with different levels of medical experience and impact in their clinical environments. Following on from this, it would be beneficial if SDM was introduced at medical school so that future MDs will be introduced to SDM earlier in their medical careers. Thus, SDM education will not be limited to those who participate in a voluntary SDM training programme. In addition, an interdisciplinary effort is required if SDM training programmes such as the Ambassador course are to fulfil their potential. This is because a patient's pathway involves contact with various health professions in the healthcare system, not only MDs. Therefore, it will be appropriate that healthcare providers in executive positions introduce SDM training programmes to their entire departments, based on their local structures and contact with patients.

Finally, there is a need for a clear definition of SDM among MDs, as well as other healthcare professionals engaging with patients, if SDM is to be implemented routinely in MDs' clinical practice.

\section{Conclusion}

Despite overall satisfaction with their learning outcomes, several ambassadors found it difficult to translate their learning outcomes into use and dissemination of SDM in their clinical practice. Thus, the programme can be improved to obtain its full potential, for example by continuous refresher courses. In addition, this study highlights the fact that action needs to be taken both at an organisational and political level for SDM to become an integral part of the clinical encounter. 


\section{Abbreviations}

\section{SDM}

Shared Decision-Making

Junior Doctors Denmark

Danish Association of Junior Doctors in Denmark

JMDs

Junior medical doctors

MDs

Medical doctors

\section{Declarations}

Ethics approval and consent to participate: According to Danish legislation as stipulated in the Act on Research Ethics Review of Health Research Projects, studies based on questionnaires and interviews that do not involve human biological material are exempt from approval by the National Committee on Health Research Ethics (https://en.nvk.dk/how-to-notify/what-to-notify). Informed written consent was obtained from all participants. The study is part of a larger project on person-centred healthcare which has been approved for processing of personal data (journal number 514-0382/19-3000) in accordance with the General Data Protection Regulation (Regulation (EU) 2016/679). All parts of the study adhered to ethical principles for medical research as presented in the Declaration of Helsinki.

Consent for publication: Not applicable.

Availability of data and materials: The data generated and analysed during the current study are available from the corresponding author on reasonable request.

Competing interest: The authors declare that they have no competing interests.

Funding: The research of the Centre for Healthy Aging is supported by Nordea-fonden, grant number [022013-0200].

Authors' contributions: MK designed the study. All authors contributed to the preparation, data collection and discussion of preliminary results. MHJ, CS, SAW and MK produced the initial draft of the manuscript. All authors contributed to and approved the final manuscript.

Acknowledgements: Not applicable.

\section{References}

1. Charles C, Gafni A, Whelan T. Shared decision-making in the medical encounter: What does it mean? (or it takes at least two to tango). Soc Sci Med. March 1997;44(5):681-92. 
2. Steffensen KD. The promise of shared decision making in healthcare. AMS Rev. June 2019;9(12):105-9.

3. Elwyn G, Tilburt J, Montori V. The ethical imperative for shared decision-making. Eur J Pers Centered Healthc. 11. June 2013;1(1):129.

4. Stiggelbout AM, Weijden TV d., Wit MPTD, Frosch D, Legare F, Montori VM, et al. Shared decision making: really putting patients at the centre of healthcare. BMJ. 27. January 2012;344(jan27 1):e256-e256.

5. Joosten EAG, DeFuentes-Merillas L, de Weert GH, Sensky T, van der Staak CPF, de Jong CAJ. Systematic Review of the Effects of Shared Decision-Making on Patient Satisfaction, Treatment Adherence and Health Status. Psychother Psychosom. 2008;77(4):219-26.

6. Shay LA, Lafata JE. Where Is the Evidence? A Systematic Review of Shared Decision Making and Patient Outcomes. Med Decis Making. January 2015;35(1):114-31.

7. Stacey D, Légaré F, Lewis K, Barry MJ, Bennett CL, Eden KB, et al. Decision aids for people facing health treatment or screening decisions. Cochrane Consumers and Communication Group, Red. Cochrane Database Syst. Rev. 2017; http://doi.wiley.com/10.1002/14651858.CD001431.pub5. Accessed January 2021.

8. Dobler CC, West CP, Montori VM. Can Shared Decision Making Improve Physician Well-Being and Reduce Burnout? Cureus 2017; http://www.cureus.com/articles/8357-can-shared-decision-makingimprove-physician-well-being-and-reduce-burnout. Accessed January 2021

9. Kane PM, Murtagh FEM, Ryan K, Mahon NG, McAdam B, McQuillan R, et al. The gap between policy and practice: a systematic review of patient-centred care interventions in chronic heart failure. Heart Fail Rev. November 2015;20(6):673-87.

10. Müller E, Strukava A, Scholl I, Härter M, Diouf NT, Légaré F, et al. Strategies to evaluate healthcare provider trainings in shared decision-making (SDM): a systematic review of evaluation studies. BMJ Open. June 2019;9(6):e026488.

11. Kienlin S, Nytrøen K, Stacey D, Kasper J. Ready for shared decision making: Pretesting a training module for health professionals on sharing decisions with their patients. J Eval Clin Pract. April 2020;26(2):610-21.

12. Légaré $F$, Ratté $S$, Gravel K, Graham ID. Barriers and facilitators to implementing shared decisionmaking in clinical practice: Update of a systematic review of health professionals' perceptions. Patient Educ Couns. December 2008;73(3):526-35.

13. Bieber C, Nicolai J, Hartmann M, Blumensteil K, Ringel N, Schneider A, et al. Training physicians in shared decision-making-Who can be reached andwhat is achieved? Elsevier 2009; https://www.sciencedirect.com/science/article/pii/S0738399109001311?via\%3Dihub. Accessed November 2020.

14. Joseph-Williams N, Lloyd A, Edwards A, Stobbart L, Tomson D, Macphail S, et al. Implementing shared decision making in the NHS: lessons from the MAGIC programme. BMJ. April 2017;j1744. 
15. Diouf NT, Menear M, Robitaille H, Painchaud Guérard G, Légaré F. Training health professionals in shared decision making: Update of an international environmental scan. Patient Educ Couns. November 2016;99(11):1753-8.

16. Singh Ospina N, Toloza FJK, Barrera F, Bylund CL, Erwin PJ, Montori V. Educational programmes to teach shared decision making to medical trainees: A systematic review. Patient Educ Couns. June 2020;103(6):1082-94.

17. Creswell JW, Plano Clark VL. Designing and conducting mixed methods research. Third edition, international student edition. Los Angeles London New Delhi Singapore Washington DC Melbourne: Sage; 2018. 492 p.

18. Attride-Stirling J. Thematic networks: an analytic tool for qualitative research. Qual Res. December 2001;1(3):385-405.

19. Chesney T, Devon K. Training surgical residents to use a framework to promote shared decisionmaking for patients with poor prognosis experiencing surgical emergencies. Can J Surg. April 2018;61(2):114-20.

20. Cohen RA, Jackson VA, Norwich D, Schell JO, Schaefer K, Ship AN, et al. A Nephrology Fellows' Communication Skills Course: An Educational Quality Improvement Report. Am J Kidney Dis. August 2016;68(2):203-11.

21. Yuen JK, Mehta SS, Roberts JE, Cooke JT, Reid MC. A Brief Educational Intervention To Teach Residents Shared Decision Making in the Intensive Care Unit. J Palliat Med. May 2013;16(5):531-6.

22. Boland L, Lawson ML, Graham ID, Légaré F, Dorrance K, Shephard A, et al. Post-training Shared Decision Making Barriers and Facilitators for Pediatric Healthcare Providers: A Mixed-Methods Study. Acad Pediatr. January 2019;19(1):118-29.

23. Körner M, Ehrhardt $H$, Steger A-K, Bengel J. Interprofessional SDM train-the-trainer program "Fit for SDM": Provider satisfaction and impact on participation. Patient Educ Couns. October 2012;89(1):122-8.

24. Pollard S, Bansback N, Bryan S. Physician attitudes toward shared decision making: A systematic review. Patient Educ Couns. september 2015;98(9):1046-57.

\section{Figures}




\begin{tabular}{|c|c|c|c|}
\hline Quantitative phase & $\begin{array}{c}\text { Planning of qualitative } \\
\text { phase }\end{array}$ & Qualitative phase & Interpretation \\
\hline $\begin{array}{l}\text { Development and } \\
\text { distribution of an } \\
\text { online survey. }\end{array}$ & $\begin{array}{l}\text { Selection of quantitative } \\
\text { results we wished to } \\
\text { explore qualitatively. }\end{array}$ & $\begin{array}{l}\text { Development of semi- } \\
\text { structured interview } \\
\text { guide. }\end{array}$ & $\begin{array}{l}\text { Interpretation of qualitative } \\
\text { findings to explain the } \\
\text { quantitative results. }\end{array}$ \\
\hline $\begin{array}{l}\text { Data collection and } \\
\text { analysis of survey data. }\end{array}$ & $\begin{array}{l}\text { Sampling of } \\
\text { interviewees. }\end{array}$ & $\begin{array}{l}\text { Generation and analysis } \\
\text { of qualitative data. }\end{array}$ & $\begin{array}{l}\text { Assessment of how the } \\
\text { quantitative and qualitative } \\
\text { data together explain the } \\
\text { research questions. }\end{array}$ \\
\hline
\end{tabular}

Figure 1

Study design and process 


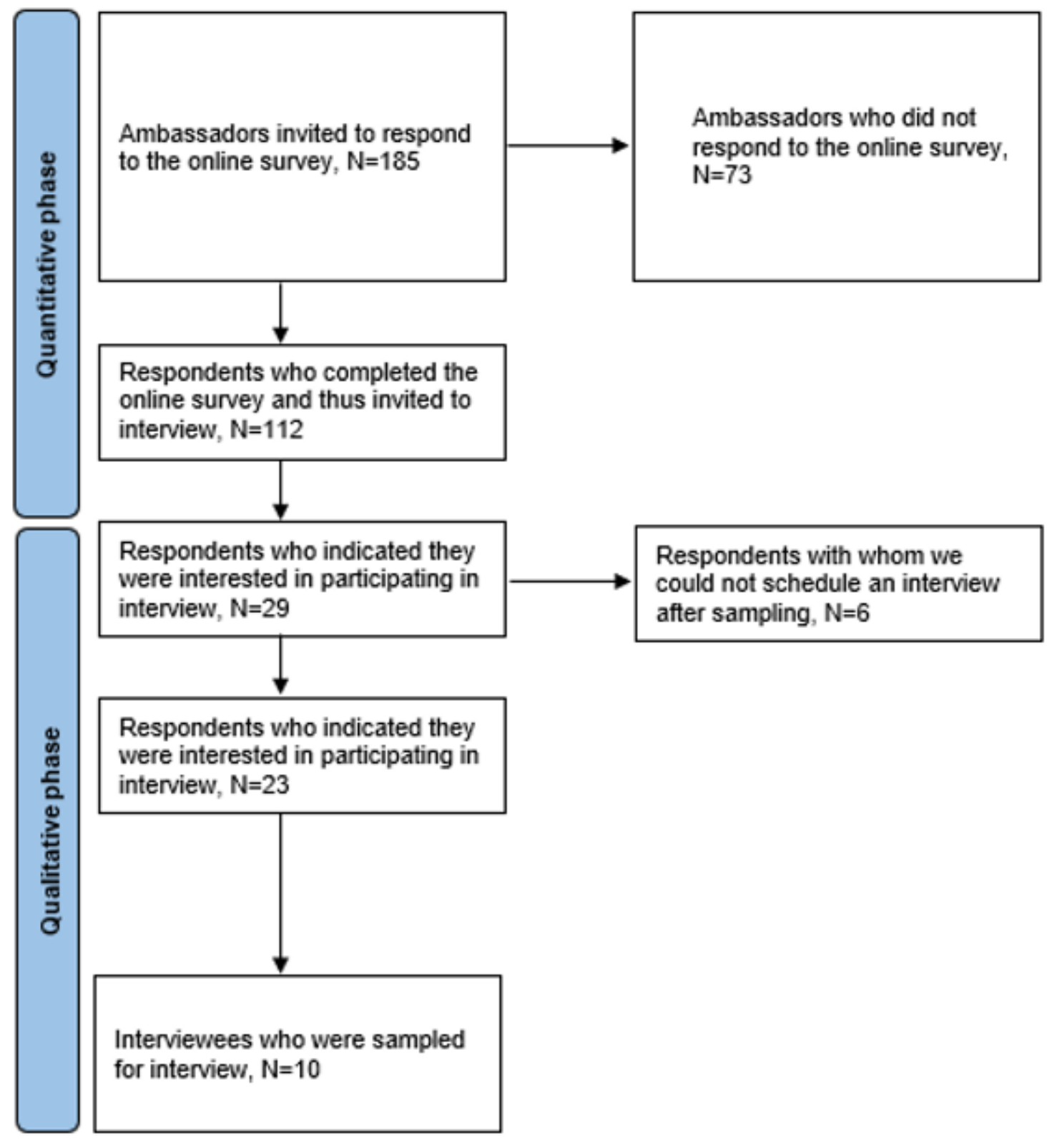

Figure 2

Flowchart of the study population and sampling of interviewees

\section{Supplementary Files}

This is a list of supplementary files associated with this preprint. Click to download.

- Additionalfile1.docx 